\title{
Thallium-201 scintigraphy for diagnosis of old myocardial infarction: comparison with electrocardiographic, ventriculographic, and coronary arteriographic findings
}

\author{
NILDA UTHURRALT, OBERDAN PARODI, SILVA SEVERI, \\ GRAHAM DAVIES, ^ ATTILIO MASERI \\ From CNR Laboratory of Clinical Physiology and Istituto di Patologia Medica I, \\ University of Pisa, Via Savi 8, Pisa, Italy
}

SUMMARY Myocardial scintigraphy with ${ }^{201} \mathrm{Tl}$ was performed at rest in a selected group of 36 patients with unequivocal clinical and electrocardiographic evidence of old myocardial infarction.

The scintigraphic findings were correlated with electrocardiographic pattern, and with regional left ventricular wall motion and the severity of coronary artery disease defined by contrast angiography. Detection was dependent on the extent of the infarct but was independent of QRS morphology and of the severity of coronary disease. When positive, ${ }^{201} \mathrm{Tl}$ scintigraphy was often a more precise method than the electrocardiogram for localising and delineating the extent of the infarct. Furthermore, the perfusion defect corresponded in location and extent to abnormalities of left ventricular wall motion. The site or severity of coronary artery disease could not be determined from the ${ }^{201} \mathrm{Tl}$ scintigram.

Myocardial scintigraphy after intravenous ${ }^{201} \mathrm{Tl}$ injection is widely used for the evaluation of patients with acute myocardial infarction ${ }^{1-3}$ and for the assessment of myocardial perfusion during stress testing. ${ }^{3}{ }^{4}$ However, the value of this technique in the detection of old myocardial infarction is still uncertain. While some investigators have reported a high degree of sensitivity, ${ }^{56}$ poor results were found by others. ${ }^{78}$ These different findings are probably related to the different selection of patients.

In order to investigate the sensitivity of this technique for the detection and localisation of old myocardial infarction we have studied a selected group of patients with old myocardial infarction defined by clinical, enzymatic, and electrocardiographic criteria. Thus, we were able to assess the relation of perfusion defects, electrocardiographic signs of infarction, abnormalities of the left ventriculograms, and the severity of coronary artery disease.

\section{Subjects and methods}

A selected population of 36 patients, aged from 35

* Wellcome Trust Research Fellow.

Received for publication 31 August 1979 to 70 years (mean 54 years), with old myocardial infarction, documented by typical clinical features, and enzymatic and electrocardiographic abnormalities, form the basis of this report. There were 29 men and seven women.

The myocardial infarction had occurred from two months to seven years before this study (mean 13.5 months).

SCINTIGRAPHIC STUDIES

${ }^{201} \mathrm{Tl}$ scintigrams were recorded at rest, in the absence of chest pain or acute electrocardiographic changes.

All scintigrams were recorded using a Jumbo Toshiba gamma camera (mod. 202) with a high sensitivity collimator and a window setting of 20 per cent about the energy peak of ${ }^{201} \mathrm{Tl}$. The camera field of view was restricted to $12 \times 12 \mathrm{~cm}$; within this field a total of 100000 counts were obtained (equivalent to between 450 and 500 thousand counts per unrestricted field) and recorded "life-size" on $x$-ray film. Imaging was begun five minutes after the intravenous injection of $1 \mathrm{mCi}$ ${ }^{201} \mathrm{Tl}, \star$ initially in the left anterior oblique (LAO) projection and then followed, in rapid succession,

* Thallium-201 was supplied by Dr R B J de Jong, NV PhilipsDuphar, Cyclotron and Isotope Laboratories, Petten, Holland. 
by a repeat LAO view and the anterior and left lateral projections. We selected the $45^{\circ}$ LAO projection as the single oblique projection providing the most information in the absence of any firm evidence to suggest that multiple oblique projections would be superior. Imaging was completed within 20 minutes of tracer injection and the whole procedure was repeated four hours later.

\section{CORONARY ARTERIOGRAPHY AND LEFT VENTRICULOGRAPHY}

Left ventriculography was performed in the right and left anterior oblique projections and recorded on $35 \mathrm{~mm}$ film at 50 frames per second. Coronary arteriography, by the Judkins technique, was performed before and after the sublingual administration of glyceryl trinitrate and recorded at 30 frames per second.

\section{ANALYSIS OF DATA}

\section{Electrocardiogram}

The electrocardiogram was analysed for the presence and location of myocardial infarction according to the criteria of the American Heart Association. ${ }^{9}$

\section{Scintigrams}

The films were analysed by two independent observers without knowledge of the electrocardiographic and angiocardiographic findings. In the event of disagreement the scintigrams were analysed by a third observer and agreement reached by at least two of the three observers. The images were graded as normal or abnormal and, from consideration of all projections, the defects were defined as anterior, inferior, posterior, or apical.

The scintigrams of 12 patients were also analysed by a computerised optical densitometer. ${ }^{10}$ After background subtraction (estimated from the lung field adjacent to the heart) two types of analysis were made: (1) interimage, between corresponding regions of the pair of early LAO scintigrams; and (2) interwall, between four regions of interest within each scintigram, namely the posterior, inferoposterior, inferoanterior, and anterior walls of the left ventricle. The activity per unit area in each region of interest was calculated and expressed as a percentage of total cardiac activity. The difference between this percentage and that of the region of highest activity was also calculated. Local density was calculated in preference to total regional activity because of the lack of an objective method of determining the boundaries of the left ventricular walls. For the purpose of densitometric analysis, a normal left ventricular wall was defined as that without electrocardiographic or ventriculographic abnormality.
For the purpose of defining normal variability a similar analysis was performed on the normal walls defined by the electrocardiogram and left ventriculogram.

\section{CORONARY ARTERIOGRAPHY AND LEFT VENTRICULOGRAPHY}

We noted the pattern of distribution of major coronary vessels to each region of the left ventricle: for the anterior wall and septum the left anterior descending (LAD) with or without the diagonal branches; for the lateral wall, the obtuse marginal branch of the left circumflex; for the inferior wall, the right coronary artery or left circumflex artery. The severity of coronary lesions was classified in the following manner: (1) complete obstruction or stenosis greater than 90 per cent, and (2) stenosis between 75 and 90 per cent (diameter reduction).

The left ventriculograms (RAO and LAO projections) were analysed for the presence and location (anterior, apical, or inferior) of wall motion abnormalities (dyssynergy). The dyssynergy was classified in two groups: (1) dyskinesia (paradoxical systolic wall motion); (2) either akinesia or hypokinesia (designated as "akinesia").

\section{LOCALISATION OF OLD MYOCARDIAL \\ INFARCTS}

The localisation of old myocardial infarcts was based on the distribution of QRS abnormalities in the current electrocardiogram. This was compared with the distribution of the ${ }^{201} \mathrm{TI}$ perfusion defects and of the ventriculographic abnormalities.

\section{Results}

\section{SCINTIGRAPHIC FINDINGS}

There were no consistent differences between corresponding scintigrams obtained within 20 minutes of ${ }^{201} \mathrm{Tl}$ injection and those recorded at four hours. No differences in the replicated LAO scintigrams were found either by visual or densitometric interimage analysis (Table 1). Densitometric

Table 1 Densitometric analysis

\begin{tabular}{|c|c|c|c|}
\hline & $\begin{array}{l}\text { No. of } \\
\text { patients }\end{array}$ & $\begin{array}{l}\text { Interimage } \\
\text { analysis } \\
(\%)\end{array}$ & $\begin{array}{l}\text { Interwall } \\
\text { analysis } \\
(\%)\end{array}$ \\
\hline Normal walls & 7 & $\begin{array}{l}5-13 \\
\bar{x} 9 \cdot 33 \pm 3.5\end{array}$ & $\begin{array}{l}6-14 \\
\bar{x} 9 \cdot 5 \pm 3 \cdot 5\end{array}$ \\
\hline $\begin{array}{l}\text { Infarcted walls (negative } \\
\text { by inspection) }\end{array}$ & 7 & $\begin{array}{l}5-12 \\
\bar{x} 9 \cdot 15 \pm 3 \cdot 0\end{array}$ & $\begin{array}{l}9-21 \\
\bar{x} 13.1 \pm 4 \cdot 3\end{array}$ \\
\hline $\begin{array}{l}\text { Infarcted walls (positive } \\
\text { by inspection) }\end{array}$ & 5 & $\begin{array}{l}6-12 \\
\bar{x} 9 \cdot 1 \pm 2 \cdot 9\end{array}$ & $\begin{array}{l}25-40 \\
\bar{x} 30 \cdot 1 \pm 10\end{array}$ \\
\hline
\end{tabular}

Results given as range, mean $(\overline{\mathrm{x}}) \pm \mathrm{SD}$. 
analysis agreed closely with analysis by inspection for the normal walls, the infarcted walls with homogeneous activity, and the infarcted walls with perfusion defects.

In the seven patients with old myocardial infarction and normal ${ }^{201} \mathrm{Tl}$ scintigrams by visual inspection which were analysed by computer, the variation in activity between the region of infarction as defined by the electrocardiogram and the normal region was $13 \cdot 1 \pm 4 \cdot 3$ per cent. Furthermore, for each of these patients, the percentage of variation was within one SD of the mean for the normal walls. However, five patients with old myocardial infarction and positive ${ }^{201} \mathrm{Tl}$ scintigrams showed a difference in activity of $30,26,35,40$, and 25 per cent in the infarcted region compared with the normal region.

Perfusion defects were seen (Fig. 1) in all eight patients with extensive anterior infarction (Fig. 2, 3), in three of 10 with anteroseptal infarction, in five of 13 with inferior infarction, and in three of five with combined anteroseptal and inferior infarction. Among the patients with inferoposterior infarction, both patients with infarction confined to the posterior wall showed unequivocal perfusion defects (Fig. 4).

The presence or absence of a perfusion defect (Fig. 5) was not necessarily related to the electrocardiographic pattern ( $Q S$ or $q R$ ). The incidence of perfusion defects was similar in patients with either a qR or QS pattern, both for inferior and anteroseptal infarcts. In the case of extensive anterior infarction, all patients showed perfusion defects regardless of QRS morphology.

In 10 of the 19 patients with positive scintigrams,

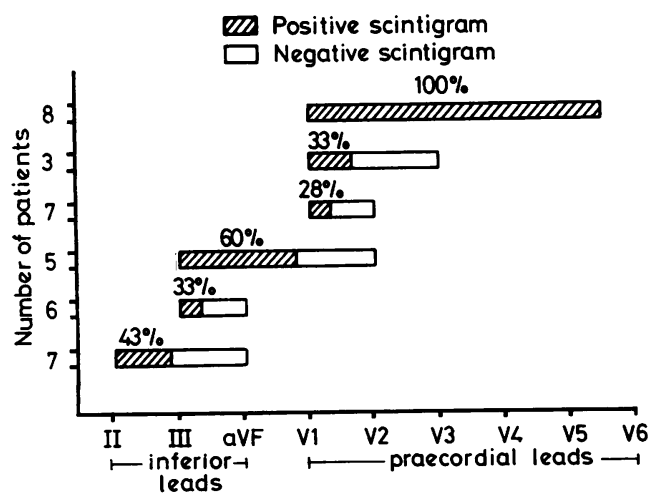

Fig. 1 Relation of ${ }^{201} \mathrm{Tl}$ scintigraphic findings to the extent of $Q$ waves. On the ordinate, the number of patients in each group. On the abscissa, bars represent the extent of $Q$ waves and the shaded regions represent the positive scintigrams. The proportion of positive scintigrams increases as $Q$ waves become more widespread.
${ }^{201} \mathrm{Tl}$ scintigraphy allowed more precise localisation and quantification of the infarct area than was possible from the electrocardiogram. The findings in two of these patients are shown in Fig. 3 and 4. The accuracy of the scintigraphic findings is confirmed by the ventriculographic abnormalities which correspond exactly in extent and location.

RELATION OF THALLIUM DEFECTS TO CORONARY ARTERIOGRAMS, ELECTROCARDIOGRAMS, AND LEFT VENTRICULOGRAMS

There were 74 regions supplied by a vessel with greater than 75 per cent stenosis in a total of 36 patients (Table 2). Dyssynergy was present in 46 regions $(62 \%), 10$ of which showed dyskinesia; electrocardiographic evidence of infarction was present in $39(53 \%)$ and a ${ }^{201} \mathrm{Tl}$ perfusion defect in $20(27 \%)$. Two of the four regions with $Q$ waves, perfusion defects, and normal wall motion were supplied by normal coronary arteries. ${ }^{201} \mathrm{Tl}$ per-

Table 2 Analysis of electrocardiographic, ventriculographic, and scintigraphic findings in regions distal to severe coronary obstruction

\begin{tabular}{rlllll}
\hline No. of regions & $Q$ waves & Akinesia & Dyskinesia & Tl defects \\
\hline 19 & + & 11 & 8 & + \\
18 & + & 16 & 2 & - \\
1 & + & - & - & + \\
1 & + & - & - & - \\
9 & - & - & - & - & - \\
26 & - & & & - \\
\hline
\end{tabular}

fusion defects were usually associated with abnormal wall motion, particularly dyskinesia $(p<0.025)$ and, invariably, with $Q$ waves. Nine regions showing akinesia were not associated with $Q$ waves or a perfusion defect but were adjacent to regions of infarction. All the regions with significant coronary disease and without either electrocardiographic or ventriculographic evidence of infarction were ${ }^{201} \mathrm{Tl}$ negative.

In the 36 patients, no consistent relation was shown between the presence or absence of complete obstruction of the corresponding coronary vessels and the presence or absence of ${ }^{201} \mathrm{Tl}$ perfusion defects (Fig. 6). Furthermore, no such relation was found when all regions with significant coronary disease were examined: perfusion defects were found in six of the 24 regions with greater than 75 per cent stenosis and in 10 of the 42 regions with greater than 90 per cent stenosis or total occlusion of the supplying vessel.

However, in all eight patients with extensive anterior infarction who exhibited a ${ }^{201} \mathrm{Tl}$ perfusion defect, a total coronary occlusion or a stenosis greater than 90 per cent was a consistent finding. 


\section{Discussion}

The design of the study, with a selection of patients with documented, unequivocal evidence of old myocardial infarction, allowed us to evaluate the diagnostic sensitivity of ${ }^{201} \mathrm{Tl}$ myocardial scintigraphy.

Our results indicate that this technique provides a fair assessment of the location and extent of myocardial tissue loss when the myocardial infarct is large. Under these conditions it appears to correlate better with the ventriculographic than with the electrocardiographic findings. However, this is not the case when myocardial tissue loss is small. In fact, only 54 per cent of the electrocardio- graphic-defined regions of infarction showed a perfusion defect.

The low incidence of positive scintigrams is not a reflection of the observer's ability to detect regional variations in activity by visual inspection of the original scintigrams. This is clearly illustrated by our results, showing no significant variations in regional activity, quantified by densitometric analysis, in the patients with infarction and negative scintigrams by visual inspection. Furthermore, the results were the same whether the original scintigrams or the computer-processed scintigrams were analysed by visual inspection.

This poor sensitivity may be related to the difficulty in detecting small infarcts, as indicated
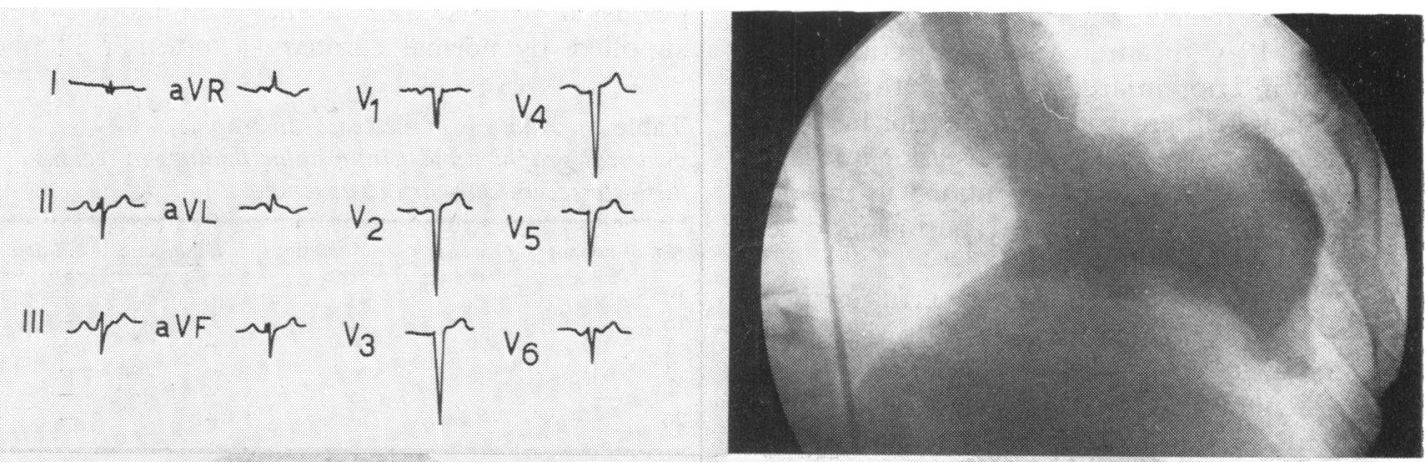

Fig. 2 Electrocardiogram, ventriculogram ( $R A O$, end-systole), and scintigrams of patient with electrocardiogramdefined, extensive, anterior infarction. LAO scintigram shows an area of reduced activity in the anteroseptal region. In the AP projection the perfusion defect involves the anterolateral wall and apex and corresponds exactly to the site of dyssynergy on the left ventriculogram. The coronary arteriograms showed greater than 90 per cent stenosis of the left anterior descending artery. 
by experimental work showing that infarcts less than $10 \mathrm{~g}$ cannot be detected in the dog even under optimum imaging conditions. ${ }^{11}$

Furthermore (1) activity in adjacent abdominal organs may obscure inferior infarcts; (2) a reduction in activity in the infarcted wall may be obscured by activity in the opposite wall, particularly in the presence of left ventricular hypertrophy; and (3) ${ }^{201} \mathrm{Tl}$ uptake may occur in islets of surviving myocardium within the region of myocardial scar.

By contrast, when ${ }^{201} \mathrm{Tl}$ scintigraphy is positive, the site of the perfusion defect accurately reflects the site of the myocardial infarct and often allows more precise delineation of its extent than does the electrocardiogram. ${ }^{201} \mathrm{Tl}$ scintigraphy examines the heart in several projections, allowing inspection of all regions of the left ventricle. However, the electrocardiographic localisation of infarction is influenced by the position of the heart, by regions of the left ventricle from which direct electrocardiographic recording is not possible (as in the case of posterior infarction), and by conduction defects which are common in the presence of old myocardial infarction.

The presence of a perfusion defect is related to the number of electrocardiographic leads showing $\mathrm{Q}$ waves, not to the type of QRS morphology. This is illustrated by the finding of perfusion defects in

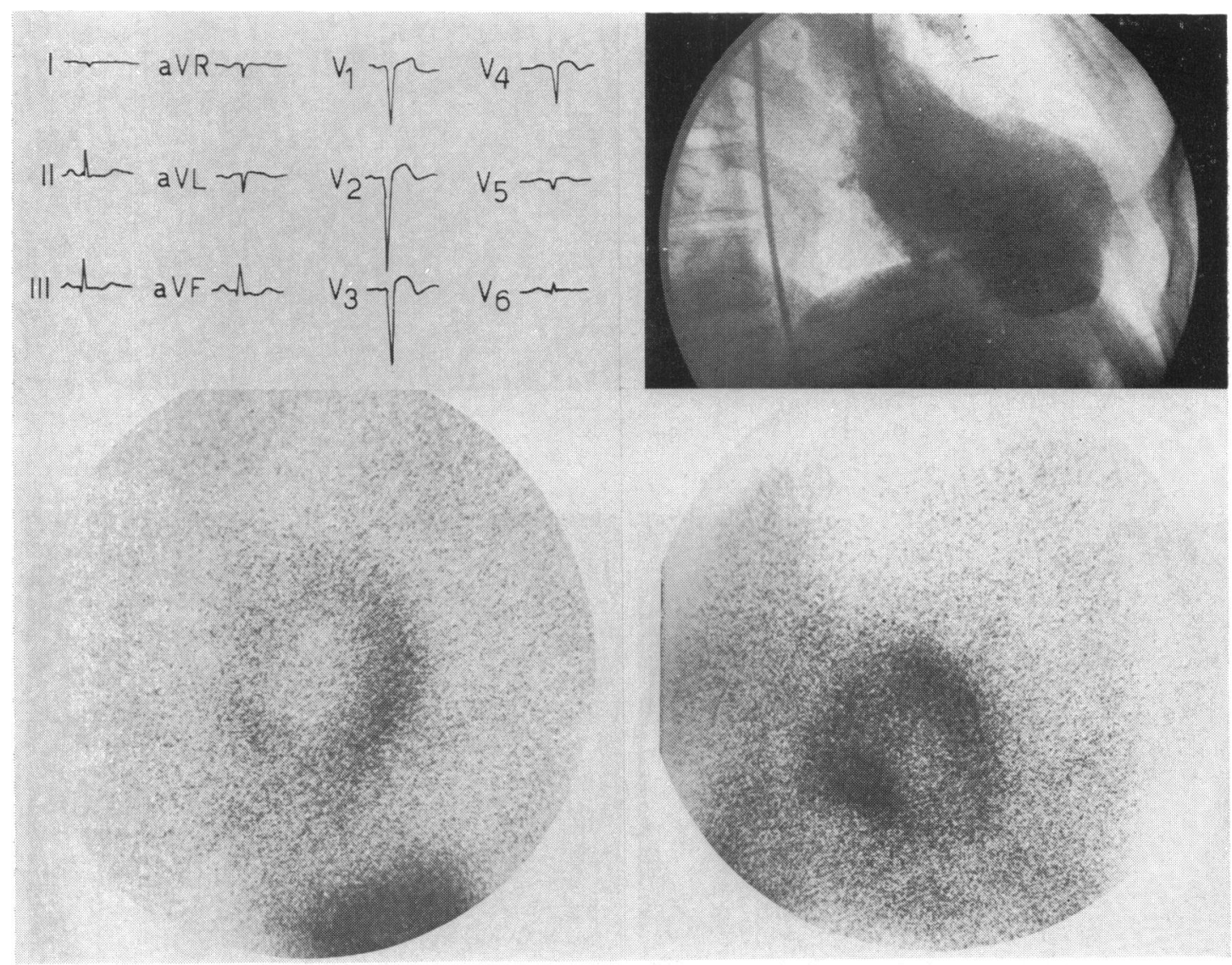

Fig. 3 Electrocardiogram, ventriculogram (RAO, end-systole), and scintigrams of patient with electrocardiogramdefined, extensive, anterior infarction similar to that of Fig. 2. The LAO scintigram shows an anteroseptal and inferior perfusion defect. The AP projection shows an apical defect, extending into the inferior wall and corresponding exactly to the site of dyssynergy on the left ventriculogram. However, no evidence of inferior infarction is seen on the electrocardiogram. Coronary arteriography showed greater than 90 per cent proximal stenosis of both the left anterior descending and circumflex arteries with a normal right coronary artery. 
all extensive anterior infarcts and by the similar incidence of perfusion defects in regions with $q R$ or QS patterns. The morphology of the QRS complex will obviously depend on the site of the exploring electrodes in relation to the site of the infarct. In a patient with $\mathrm{qR}$ complexes recorded in the classical praecordial lead positions, QS complexes may be recorded by changing the location of the recording electrodes. Inferior wall electrical activity is recorded by only three leads which are placed at a site remote from the infarct. Furthermore, the exact QRS morphology is timedependent, thus $\mathrm{qR}$ complexes may be recorded at sites previously showing QS complexes. For the above reasons the QRS morphology does not indicate the extent of the infarct and, because of this, does not correlate with the presence or absence of ${ }^{201} \mathrm{Tl}$ perfusion defects.

The 74 per cent concurrence between the presence of $Q$ waves and dyssynergy agrees with previous reports. ${ }^{12}$ Of the regions showing discordance between electrocardiographic and ventriculographic abnormalities, two were posterior, a region difficult to evaluate by ventriculography, ${ }^{13}$ and one was non-transmural; eight showed dyssynergy without $Q$ waves or perfusion defect. These latter findings can be explained on the basis of a small scar, by interference with the synchronous contraction of the surrounding normal myocardium, producing disproportionately large ventriculographic abnormalities. ${ }^{14}$ For this same reason, dyssynergy was less often related to perfusion

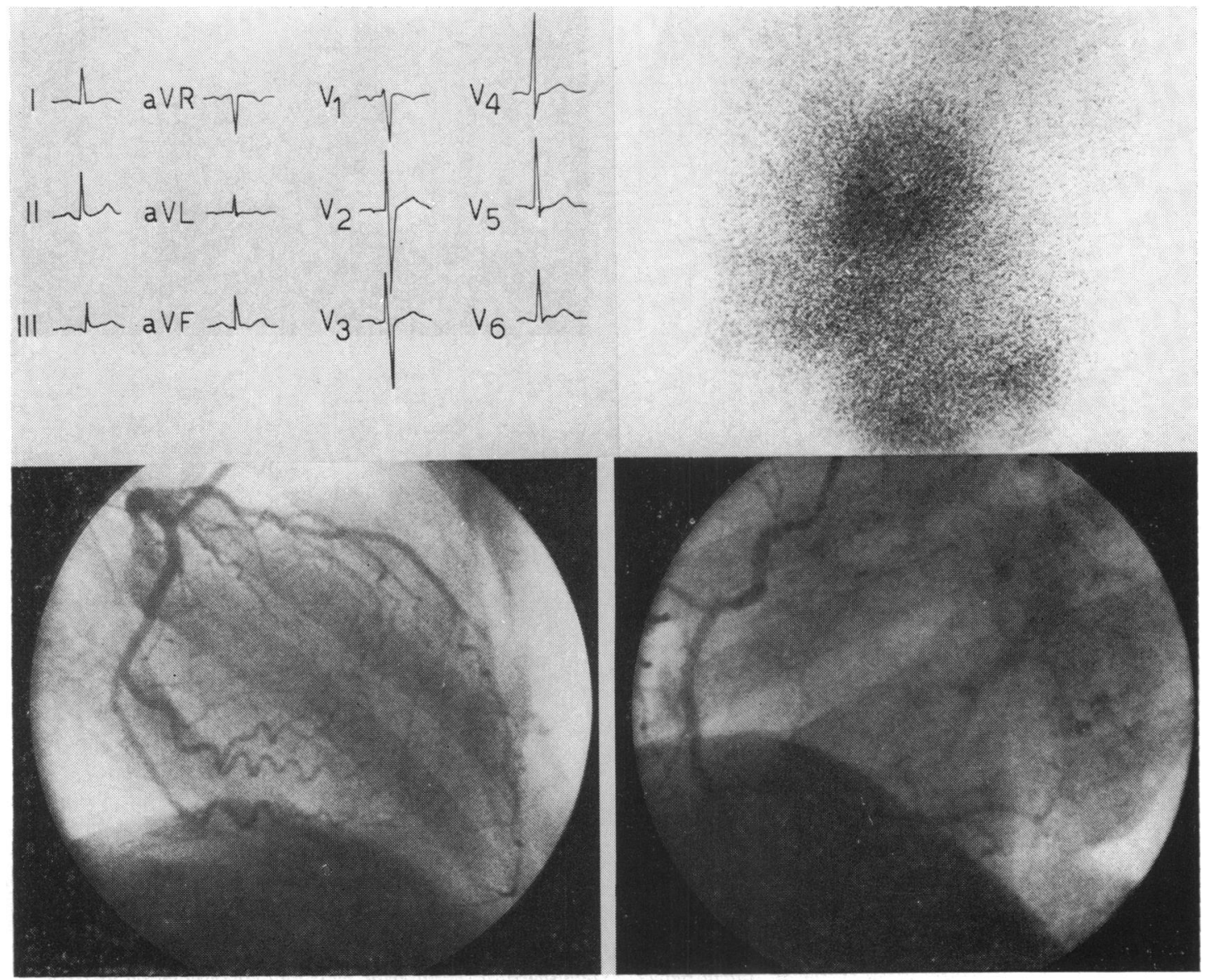

Fig. 4 The presence of posterior infarction is more clearly demonstrated by the scintigram (LAO projection) than by the electrocardiogram. Furthermore, the infarcted region is supplied by normal coronary vessels, the only lesion being in the proximal part of the left anterior descending artery. 


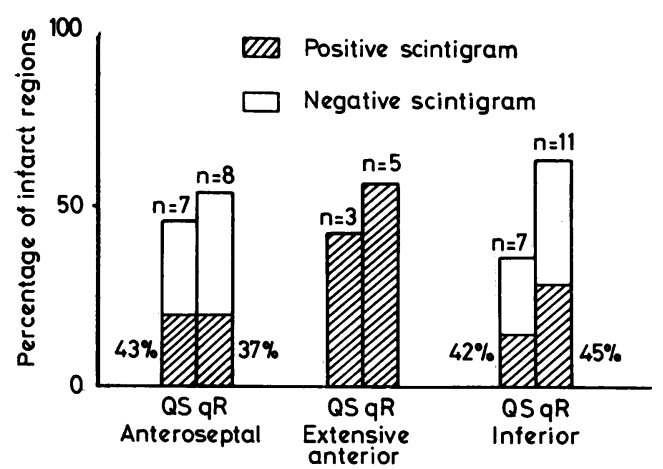

Fig. 5 Relation of ${ }^{201} \mathrm{Tl}$ scintigraphic findings to $Q R S$ morphology in 41 regions of left ventricular infarction. On the ordinate is the percentage of regions of each infarct site (anteroseptal, extensive anterior, inferior) showing $Q S$ or $q R$ complexes. For each infarct site and $Q R S$ morphology, the total number of regions and the percentage which are ${ }^{201} \mathrm{Tl}$ positive are given. Positive ${ }^{201} \mathrm{Tl}$ scintigrams are related to myocardial infarct extent, not to $Q R S$ morphology.

defects than were $Q$ waves, thallium scintigraphy being unable to detect small scars.

Other workers have found that old myocardial infarction is associated with severe coronary artery disease. ${ }^{8} 15$ Furthermore, Blood et al. ${ }^{15}$ found resting ${ }^{201} \mathrm{Tl}$ perfusion defects in only 54 per cent of their patients. We also found positive resting ${ }^{201} \mathrm{Tl}$ scintigrams in 54 per cent (19) of our patients. However, in contrast to the findings of the above authors, we found that previous myocardial infarction was associated with a variable severity of coronary disease. Thirty-one per cent (six) of our patients with positive ${ }^{201} \mathrm{Tl}$ scintigrams had less than 90 per cent coronary obstruction and, conversely, 11 patients with infarction and negative resting ${ }^{201} \mathrm{Tl}$ scintigrams had greater than 90 per cent stenosis. It therefore appears that resting ${ }^{201} \mathrm{Tl}$ perfusion defects and infarction are not necessarily related to the severity of coronary artery disease. Severe coronary artery disease is not necessarily

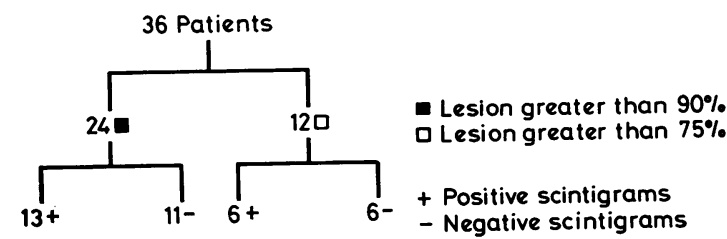

Fig. 6 Relation of ${ }^{201} \mathrm{Tl}$ scintigraphic findings to the severity of coronary artery disease. The presence of a perfusion defect on ${ }^{201} \mathrm{Tl}$ scintigrams recorded at rest is. independent of the severity of coronary artery disease in patients with old myocardial infarction. associated with myocardial infarction and the converse is also true. ${ }^{16}{ }^{17}$ The reasons for this include the presence of collateral vessels, ${ }^{18-20}$ and the possibility of functional changes ${ }^{19} 21$ in coronary vessels with a variable degree of atheromatous disease.

\section{Conclusions}

(1) When thallium scintigraphy is negative it does not rule out the presence of myocardial scar or abnormalities of wall motion.

(2) A resting thallium perfusion defect usually indicates the presence of moderate or severe infarction, with its associated abnormality of left ventricular function, and often localises and delineates the infarct with greater precision than the electrocardiogram.

(3) Regardless of whether thallium scintigraphy is positive or negative, it cannot be used to determine reliably either the site or the severity of coronary artery disease.

\section{References}

'Wackers FJT, Schoot JB Vd, Sokoke EB, et al. Noninvasive visualization of acute myocardial infarction in man with thallium-201. Br Heart $\mathcal{F}$ 1975; 37: 741-4. ${ }^{2}$ Pohost GM, Zir LM, Moore RH, McKusick KA, Guiney TE, Beller GA. Differentiation of transiently ischemic from infarcted myocardium by serial imaging after a single dose of thallium-201. Circulation 1977; 55: 294-302.

${ }^{3}$ Ritchie JL, Zaret BL, Strauss HW, et al. Myocardial imaging with thallium-201: a multicentre study in patients with angina pectoris or acute myocardial infarction. Am f Cardiol 1978; 42: 345-50.

${ }^{4}$ Bailey IK, Lawrence SC, Rouleau J, Strauss HW, Pitt B. Thallium-201 myocardial perfusion imaging at rest and during exercise. Comparative sensitivity to electrocardiography in coronary artery disease. Circulation 1977; 55: 79-87.

${ }^{5}$ McLaughlin PR, Martin RP, Doherty $\mathrm{P}$, et al. Reproducibility of thallium-201 myocardial imaging. Circulation 1977; 55: 497-503.

${ }^{6}$ Botvinick EH, Taradash MR, Shames DM, Parmley WW. Thallium-201 myocardial perfusion scintigraphy for the clinical classification of normal, abnormal and equivocal electrocardiographic stress test. $\mathrm{Am} \mathcal{F}$ Cardiol 1978; 41 : 43-51.

'Wackers FJT, Sokole EB, Samson G, et al. Value and limitations of thallium-201 scintigraphy in the acute phase of myocardial infarction. N Engl f Med 1976; 295: $1-5$.

${ }^{8}$ Bodenheimer MM, Banka VS, Fooshee C, Hermann GA, Helfant R. Relationship between regional myocardial perfusion and the presence, severity and reversiblity of asynergy in patients with coronary heart disease. Circulation 1978; 58: 789-95. 
${ }^{9}$ American Heart Association. A Report of the Ad Hoc Committee for Grading of Coronary Artery Disease, Council on Cardiovascular Surgery. A reporting system on patients evaluated for coronary artery disease. Circulation 1975; 51 (4): 5-28.

${ }^{10}$ Bencivelli W, Parodi O, Michelassi C, Uthurralt N, Severi S, Maseri A. A computerized, densitometric analysis of thallium-201 myocardial scintigrams. Trans Eur Soc Cardiol 1978; 1: 17.

${ }^{11}$ Mueller TM, Marcus ML, Ehrhardt JC, Chaudhuri T, Abboud FM. Limitations of thallium-201 myocardial perfusion scintigrams. Circulation 1976; 54: 640-6.

${ }^{12}$ Bodenheimer M, Banka VS, Helfant RH. Q waves and asynergy: predictive value and hemodynamic significance of anatomic localization (abstract). Am F Cardiol 1974; 33: 128.

${ }^{13}$ Williams RA, Cohn PF, Vokonas PS, Young E, Herman MV, Gorlin R. Electrocardiographic, arteriographic and ventriculographic correlations in transmural myocardial infarction. Am f Cardiol 1973; 31: 595-9.

${ }^{14}$ Bodenheimer MM, Banka VS, Hermann GA, Trout RG, Pasdav H, Helfant RH. Reversible asynergy: histopathologic and electrocardiographic correlations in patients with coronary artery disease. Circulation 1976; 53: 792-6.

${ }^{15}$ Blood DK, McCarthy DM, Sciacca RR, Cannon PJ.
Comparison of single-dose and double-dose thallium201 myocardial perfusion scintigraphy for the detection of coronary artery disease and prior myocardial infarction. Circulation 1978; 58: 777-88.

16Baroldi G, Radice F, Schmid G, Leone A. Morphology of acute myocardial infarction in relation to coronary thrombosis. Am Heart f 1974; 87: 65-75.

${ }^{17}$ Eliot RS, Baroldi G, Leone A. Necropsy studies in myocardial infarction with minimal or no coronary luminal reduction due to atherosclerosis. Circulation 1974; 49: 1127-31.

${ }^{18}$ Helfant RH, Vokonas PS, Gorlin R. Functional importance of human coronary collateral circulation. $N$ Engl f Med 1971; 284: 1277-81.

${ }^{19}$ Baroldi G. Coronary stenosis: ischemic or nonischemic factor? Am Heart $\mathcal{f}$ 1978; 96: 139-43.

${ }^{20} \mathrm{Cohen} \mathrm{MV}$. The functional value of coronary collaterals in myocardial ischemia and therapeutic approach to enhance collateral flow. Am Heart f 1978; 95: 396-404. ${ }^{21}$ Maseri A, L'Abbate A, Baroldi G, et al. Coronary vasopasm as a possible cause of myocardial infarction. $N$ Engl F Med 1979; 299: 1271-7.

Requests for reprints to Dr N Uthurralt, Laboratorio di Fisiologia Clinica CNR, Via Savi 8, 56100Pisa, Italy. 